\title{
Opinion on evolution of air quality models (AQM)
}

\section{Opinion}

This opinion presents evolution of air quality models (AQM), i.e., air pollution modeling techniques for the simulation of air quality processes. The review includes models developed or recommended by governmental agencies for regulatory applications. Non-reactive models (e.g., plume or dispersion models) are discussed.

\section{What is the air quality models (AQM)?}

It is a mathematical formulation describing the relationship between atmospheric concentrations, emissions levels, meteorology, deposition, chemical transformation, and removals. Air pollution monitoring give qualitative and quantitative data about pollutants concentrations in ambient air and deposition, but they can only describe air quality at specific sites and period times, without giving clear identification of the causes of the air quality problems. Modeling of air pollution, can give a complete description of the air quality problem, an analysis of causes and factors (emission sources, chemical and physical changes, meteorological processes, and the mitigation measures). ${ }^{1-3}$

\section{Why do we use AQM?}

I. It helps to answer the following questions:

II. What is the source's contribution to the pollutant concentrations at the site to be studied?

III. What is the most effective strategy for reducing pollutant concentrations

IV. What is the effect on air quality

V. Where should one place a source of pollution in the future?

VI. What will the air quality be like in the future?

Modeling of Point Sources is one of the first challenges in the history of air pollution modeling. ${ }^{4}$ It was the understanding of the diffusion properties of plumes emitted from industrial stacks.

\section{Evolution of AQM}

Generation stages of evolution Air Quality Models:

1. During (1970s - 1980s): dispersion models (e.g., Gaussian plume models) and photochemical box models was developed.

2. During (1980s - 1990s): photochemical grid models were developed.

3. During (1990s - 2000s): community-based modeling system was developed.

\section{Types of AQM}

Air Quality Models are classified into: ${ }^{5,6}$

a) Emission Models: this evaluates spatial and temporal emission rates based on emission rate, activity level, and meteorology parameters.

b) Meteorological Models: this estimates dispersion, transport, vertical mixing and moisture and space.
Volume 7 Issue 3 - 2021

\author{
Atef MF Mohammed \\ Air Pollution Research Department, Environmental Research \\ Division, National Research Center, Egypt
}

\author{
Correspondence: Atef MF Mohammed, Air Pollution Research \\ Department, Environmental Research Division, National \\ Research Center, Giza, Egypt, Tel +20 I I I I | 43456, +20 2 \\ 3337।362, Fax +2023337093। \\ Email ateffathy2006@yahoo.com \\ Received: April 30, 2021 | Published: May 17, 2021
}

c) Chemical Model: this estimates transformation of gases to secondary particles and gases, emitted particles transformation, and evaluate equilibrium between particles and gas for volatile compounds.

d) Source Dispersion Model: it uses the outputs from the previous models to evaluate concentrations levels at receptors, vertical mixing, dispersion, deposition and chemical transformation, and transport.

e) Receptor Model: it estimates contributions from different primary source emissions or from multivariate monitoring taken at one or more receptor locations.

\section{Classifications of AQM}

A. According to types and number of pollutants and exposure time periods:

1. Short-term models: used for a few hours to a few days; worst case episode conditions.

2. Long-term models: used to predict seasonal or annual average level concentrations; health effects due to pollutants exposure.

B. According to coordinate system used:

1. Grid-based: region divided into an array of cells, and used to evaluate compliance with National Ambient Air Quality Standards (NAAQS).

2. Trajectory: it study plume as it moves downwind direction.

\section{What are the most model inputs?}

Figure 1 shows model inputs for AQM.

A. Emissions levels: this uses man-made emissions of pollutants such as ( $\mathrm{PM}, \mathrm{NO}, \mathrm{NO}_{2}, \mathrm{SO}_{2}, \mathrm{O}_{3}, \mathrm{NH}_{3}, \mathrm{H}_{2} \mathrm{~S}, \mathrm{CO}$ and VOCs).

B. Meteorology: this uses wind (speed and direction), humidity, temperature, precipitation, clouds, vertical mixing, etc. 
C. Land-use Conditions: this uses pollutant concentrations at the boundaries which show transport from outside locations to the site modeled.

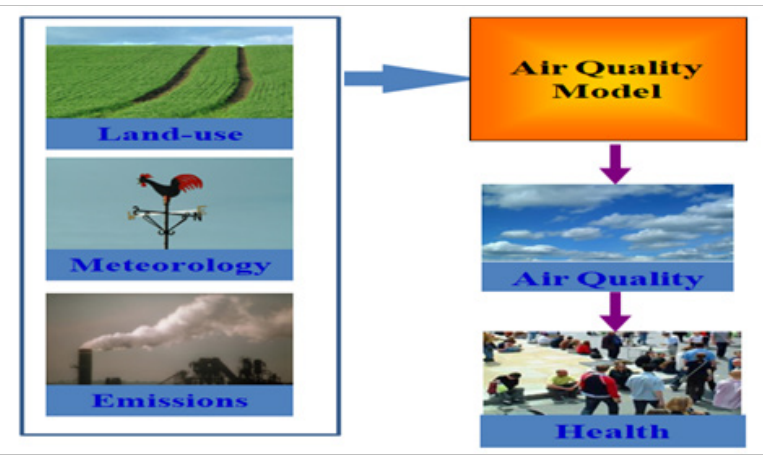

Figure I Shows model inputs for AQM.

\section{Examples of dispersion models $\mathbf{s}^{7-10}$}

1) Gaussian Dispersion Models: plume dispersion and shape were varying in according to vertical, crosswind of the plume and meteorological conditions.

2) Atmospheric Dispersion Modeling System (ADMS): It was developed by Cambridge Environmental Research Consultants (CERC) of the UK. It is atmospheric pollution dispersion model for evaluating concentrations levels of atmospheric pollutants emitted continuously from point, area, line and volume sources. The first version of ADMS was released in 1993. ADMS can model up to 100 emission sources with each other, up to 6 may be line, area or volume sources, and up to 100 may be point sources.

3) American Meteorological Society/ Environmental ProtectionAgency Regulatory Model(AERMOD): It was developed by the American Meteorological Society (AMS)/ United States Environmental Protection Agency (EPA) on 2000. It used for: Multiple point, area and volume sources, urban or rural locations, and plume dispersion. It is includes three modules: i) a steady-state dispersion model used for short-length dispersion of emissions from stationary sources (up to $50 \mathrm{~km}$ ); ii) a meteorological data (AERMET) that deals with meteorological parameters, ambient air soundings, and monitoring data from on-site station towers; and iii) atmospheric parameters such as: mixing heights, atmospheric turbulence characteristics, friction velocity, surface heat flux; and a terrain preprocessor.

4) California Puff (CALPUFF) model: It is an integrated modeling system used for the modeling dispersion of atmospheric pollution. The model was developed in the late 1980s by the Sigma Research Corporation (SRC), USA. The modeling system consists of three main components: CALMET (a diagnostic 3-dimensional meteorological model), CALPUFF (an air quality dispersion model), and CALPOST (a post processing package).

5) Industrial Source Complex model (ISC3): it is a steadystate Gaussian plume model which can be used to estimate pollutant concentration levels from a variety of sources related to an industrial complex. This model can be used for point, line, area, and volume sources; long-term and short-term; and settling and dry deposition of particles. The screening version of ISC3 is SCREEN3. Input data required for short term version were three types: i) source information such as: emission rate, dimensions of the source, and release height of the emission source; ii) meteorological parameters such as: ambient temperature $(\mathrm{K})$, wind speed $(\mathrm{m} / \mathrm{s})$, wind direction, atmospheric stability classes, and urban and rural mixing height $(\mathrm{m})$.

\section{Acknowledgments}

None.

\section{Conflicts of interest}

The authors declare that there are no conflicts of interest.

\section{References}

1. Builtjes P. The Problem - Air Pollution. Chapter 1 of AIR QUALITY MODELING - Theories, Methodologies, Computational Techniques, and Available Databases and Software. In: Zannetti P, editor. Vol I Fundamentals. EnviroComp Institute and Air \& Waste Management Association;2003.

2. Daly A, Zannetti P. Air Pollution Modeling - An Overview. In: Zannetti P, Al-Ajmi D, editors. Chapter 2 of Ambient Air Pollution. The Arab School for Science and Technology (ASST); The Enviro Comp Institute; 2007.

3. Daly A, Zannetti P. Air Pollution Modeling - An Overview. In: Zannetti P, Al-Ajmi D, editors. Chapter 2 of Ambient Air Pollution. The Arab School for Science and Technology. 2007.

4. Bosanquet CH. The Spread of Smoke and Gas from Chimmneys. Trans. Faraday Soc. 1936;32:1249.

5. Amitava B. Dispersion Modeling in assessing air quality of industrial projects under Indian regulatory regime. Energy and Environment. 2010;1(1):97-112.

6. Zhong S, Zhou L. Software for Environmental Impact Assessment of Air Pollution Dispersion Based on ArcGIS. Procedia Environmental Sciences. 2011;10:2792-2797.

7. USEPA (U.S. Environment Protection Agency). User's Guide for the Industrial Source Complex (ISC3). Dispersion Models Volume II- Description of Model Algorithms. EPA-454/B-95-003b. Research Triangle Park, NC, USA. U.S. Environment Protection Agency; 1995A.

8. USEPA (U.S. Environment Protection Agency). SCREEN3 Model User's Guide. EPA-454/B-95-004. U.S. Research Triangle Park, NC, USA. Environment Protection Agency; 1995B.

9. USEPA (U.S. Environment Protection Agency). Addendum - User's Guide for the AMS/EPARegulatory Model - AERMOD. Office of Air Quality Planning and Standards, Research Triangle Park, NC, EPA454/B-03-001. 2014.

10. ADMGO (Air Dispersion Modeling Guideline for Ontario). Version 3, Guidance A-11 for Demonstrating Compliance with the Air Dispersion Modeling Requirements set out in Ontario Regulation 419/05 Air Pollution - Local Air Quality made under the Environmental Protection Act, PIBs \# 5165e03 Air Dispersion Modeling Guideline for Ontario. Ontario Ministry of the Environment and Climate Change February 2017; 2017. 